\title{
Bubble Drift Velocity from the Bed Collapse Technique in Three-Phase Fluidized Beds
}

\author{
Sung Soo Park, Seok Min Kang, Dong Hyun Leeł, Young Kwan Lee, Ji-Heung Kim, Gui Young Han, \\ Norman Epstein*, John R. Grace* and Sang Done Kim** \\ Department of Chemical Engineering, Sungkyunkwan Univ., Suwon 440-746, Korea \\ *Department of Chemical and Biological Engineering, University of British Columbia, Vancouver, Canada, V6T 1Z4 \\ **Department of Chemical \& Biomolecular Engineering and Energy \& Environment Research Center, \\ Korea Advanced Institute of Science and Technology, Daejeon 305-701, Korea \\ (Received 15 November $2004 \bullet$ accepted 17 December 2004)
}

\begin{abstract}
Transient behavior of a bed collapsing after cut-off of gas supply into a three-phase fluidized bed was determined in a $0.21 \mathrm{~m}$-diameter half-tube acrylic column having a test section $1.8 \mathrm{~m}$ high. The transient behavior of the bed collapse after cut-off of the gas supply to the beds was monitored by a video camera ( 30 frames/s). A theory was developed to account for the dynamic behavior of the bed collapse after the gas supply shut-off to three-phase fluidized beds. The bubble drift velocity was theoretically calculated by gas and liquid phase holdups at steady state condition. At a liquid velocity of $0.103 \mathrm{~m} / \mathrm{s}$ and gas velocity of $0-0.023 \mathrm{~m} / \mathrm{s}$, bubble size was uniform in the dispersed bubble flow regime. However, as the gas velocity increased above $0.023 \mathrm{~m} / \mathrm{s}$, the discrete or coalesced bubble flow regime could be observed. The agreement between the predicted and experimental values is acceptable in the dispersed bubble flow regime, but the agreement becomes poorer with increasing gas velocity.
\end{abstract}

Key words: Bed Collapse, Bubble Drift Velocity, Three-Phase Fluidized Beds, Gas Holdup

\section{INTRODUCTION}

In most three-phase fluidized beds, the liquid is the continuous phase and both the gas bubbles and the solid particles are dispersed phases [Lee et al., 1993; Park and Kim, 2003]. Three-phase fluidized beds have been applied to many industrial processes, such as wastewater treatment, hydrogenation and electrowinning processes [Fan, 1989; Han et al., 2003; Kwauk, 1992; Lee et al., 2000].

Jin and Zhang [1990] conducted bed collapsing experiments to determine the parameters $\mathrm{k}$ and $\mathrm{x}$ in the generalized wake model [Bhatia and Epstein, 1974] of three-phase fluidized beds. Chen and Fan [1990] have presented a theory to explain the dynamic behaviour of bed collapse in a three-phase fluidized bed after a sudden stop of gas and liquid flows. They also reported that the predicted dynamic behaviour of the bed collapse by the proposed theory agrees well with the experimental data. In their theory, they assumed a liquidsolid sedimentation region after a sudden stop of gas and liquid flows. However, previous studies [Maucci et al., 1999; Fan, 1999] found that many bubbles were trapped in the liquid-solid packed-bed region since heavy particles quickly moved downward. Following from this work, Lee et al. [2003] recently reported transient behaviour of the bed collapse after shutting off the gas supply at a constant liquid velocity above the minimum fluidization velocity in threephase fluidized beds.

The objectives of this study are to develop a theory to account for the dynamic behaviour of the bed collapse after suddenly interfering the gas flow in three phase fluidized beds and to compare the experimental results with the predicted values from the model equations.

To whom correspondence should be addressed.

E-mail: dhlee@skku.edu

\section{THEORY}

The transient behaviour of the bed collapsing process after a sudden stop of gas flow in three phase fluidized beds is shown in Fig. 1 . The mass balances for individual phases across boundary 1 are

$$
\begin{aligned}
& \text { Gas: }\left(\mathrm{V}_{g 2}-\mathrm{C}_{1}\right)=0 \\
& \text { Liquid: }\left(\mathrm{V}_{l 2}-\mathrm{C}_{1}\right) \varepsilon_{10}=\left(\mathrm{V}_{l 1}-\mathrm{C}_{1}\right) \mathcal{\varepsilon}_{l 1}^{\prime \prime} \\
& \text { Solid: }\left(\mathrm{V}_{s 2}-\mathrm{C}_{1}\right)\left(1-\varepsilon_{10}-\varepsilon_{g 0}\right)=\left(\mathrm{V}_{s 1}-\mathrm{C}_{1}\right)\left(1-\varepsilon_{11}^{\prime \prime}\right)
\end{aligned}
$$

In Eqs. (1)-(3), the phase holdups in region 2 in the dynamic system are assumed to be the same as those of the original steady-state operation in Fig. 1(a). The solid holdup in region 1 of the dynamic system is assumed to be the same as that of the liquid-solid fluidized beds at $\mathrm{U}_{l}=\mathrm{U}_{10}$. Under this premise, the relative motion between the gas phase and the solid phase in region 2 of the dynamic bed should be the same as in Fig. 1(a):

$$
\left(\mathrm{V}_{s 2}-\mathrm{V}_{g 2}\right)=-\frac{\mathrm{U}_{g 0}}{\varepsilon_{g 0}}
$$

The upward velocities of individual phases in the liquid-solid fluidized region are as follows:

$$
\mathrm{V}_{l 1}=\frac{\mathrm{U}_{l 0}}{\varepsilon_{l 1}^{\prime \prime}}
$$

and

$$
\mathrm{V}_{s 1}=0
$$

Thus, there are six governing Eqs. (1)-(6) for the dynamic system and six unknowns $\left[\mathrm{C}_{1}, \mathrm{~V}_{l 1}, \mathrm{~V}_{s 1}, \mathrm{~V}_{g 2}, \mathrm{~V}_{12}\right.$ and $\left.\mathrm{V}_{s 2}\right]$. Eqs. (1)-(6) can be solved by combining Eqs. (1), (3) and (4), and $\mathrm{V}_{g^{2}}$ can be expressed as 


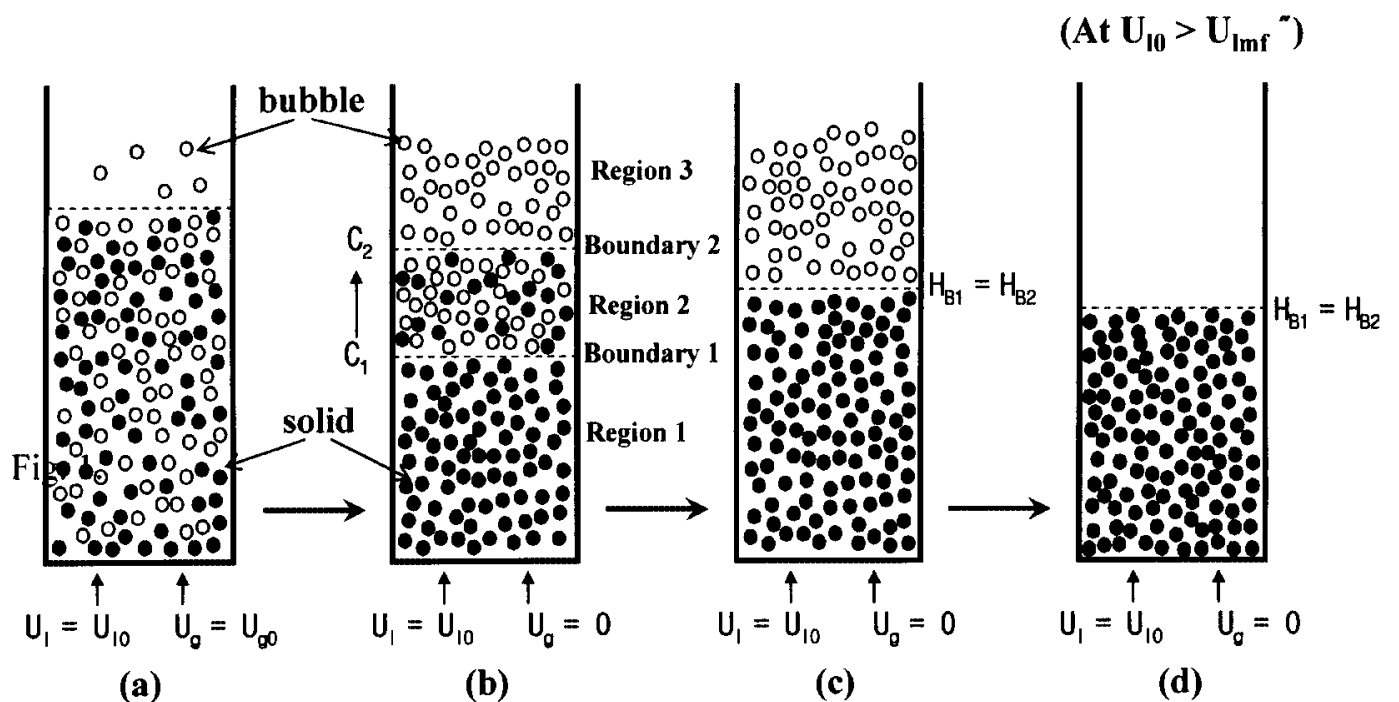

(a)

(b)

(c)

(d)

Fig. 1. Bed collapsing process after suddenly cut-off of air with constant liquid velocity.

$$
\mathrm{V}_{g 2}=\mathrm{C}_{1}=\frac{\frac{\mathrm{U}_{g 0}}{\varepsilon_{g 0}}\left(1-\varepsilon_{10}-\varepsilon_{g 0}\right)}{1-\mathcal{E}_{l 1}^{\prime \prime}}
$$

Combining Eqs. (2), (5) and (7), $\mathrm{V}_{12}$ becomes

$$
\mathrm{V}_{l 2}=\frac{\mathrm{U}_{g 0}\left(1-\varepsilon_{l 0}-\varepsilon_{80}\right)}{\varepsilon_{g 0}\left(1-\varepsilon_{l 1}^{\prime \prime}\right)} \frac{\varepsilon_{l 0}-\varepsilon_{11}^{\prime \prime}}{\varepsilon_{l 0}}+\frac{\mathrm{U}_{l 0}}{\varepsilon_{l 0}}
$$

Combining Eqs. (4) and (7), $\mathrm{V}_{s 2}$ can be expressed as

$$
\mathrm{V}_{s 2}=\frac{\mathrm{U}_{g 0}\left(\varepsilon_{l 1}^{\prime \prime}-\varepsilon_{l 0}-\varepsilon_{g 0}\right)}{\varepsilon_{g 0}\left(1-\varepsilon_{l 1}^{\prime \prime}\right)}
$$

The bubble rise velocity, $\mathrm{U}_{b}$, can be written as

$$
\mathrm{U}_{b}=\frac{\mathrm{U}_{g 0}}{\varepsilon_{g 0}}=\frac{\mathrm{U}_{g 0}+\mathrm{U}_{10}}{\varepsilon_{80}+\varepsilon_{l 0}}+\mathrm{U}_{b d}
$$

Here $\mathrm{U}_{b d}$ is the bubble drift velocity in the three-phase fluidized beds, related to other system variables by

$$
\mathrm{U}_{b d}=\left(\frac{\mathrm{C}_{1} \varepsilon_{s 1}^{\prime \prime} \varepsilon_{10}}{\varepsilon_{s 0}}-\mathrm{U}_{10}\right) \frac{1}{1-\varepsilon_{s 0}}
$$

where $\varepsilon_{s 1}^{\prime \prime}$ is solid holdup below the bubble swarm (boundary 1) and is equal to the solid holdup at $\mathrm{U}_{n}$ in liquid-solid fluidized beds.

Combining Eqs. (7) and (11),

$$
\mathrm{U}_{b d}=\frac{\varepsilon_{10}}{1-\varepsilon_{s 0}}\left(\frac{\mathrm{U}_{g 0}}{\varepsilon_{g 0}}-\frac{\mathrm{U}_{l 0}}{\varepsilon_{l 0}}\right)=\frac{\mathrm{j}_{g l}}{\varepsilon_{g 0}}
$$

Eq. (12) is in the form of the drift flux for a three-phase system, as reported by El-Temtamy and Epstein [1980], Saberian-Broudjenni et al. [1984], Chern et al. [1984] and Chen and Fan [1990].

\section{EXPERIMENTAL}

Experiments were carried out in a 0.21-m diameter half-tube acrylic column having a test section of $1.8 \mathrm{~m}$-high (Fig. 2). The particles were $3.1 \mathrm{~mm}$ glass beads $\left(\rho_{s}=2,475 \mathrm{~kg} / \mathrm{m}^{3}\right)$ as the solid phase. Deionized water and air were used as the liquid and gas phase, respectively. The particles were fluidized by cocurrent upflow of liquid

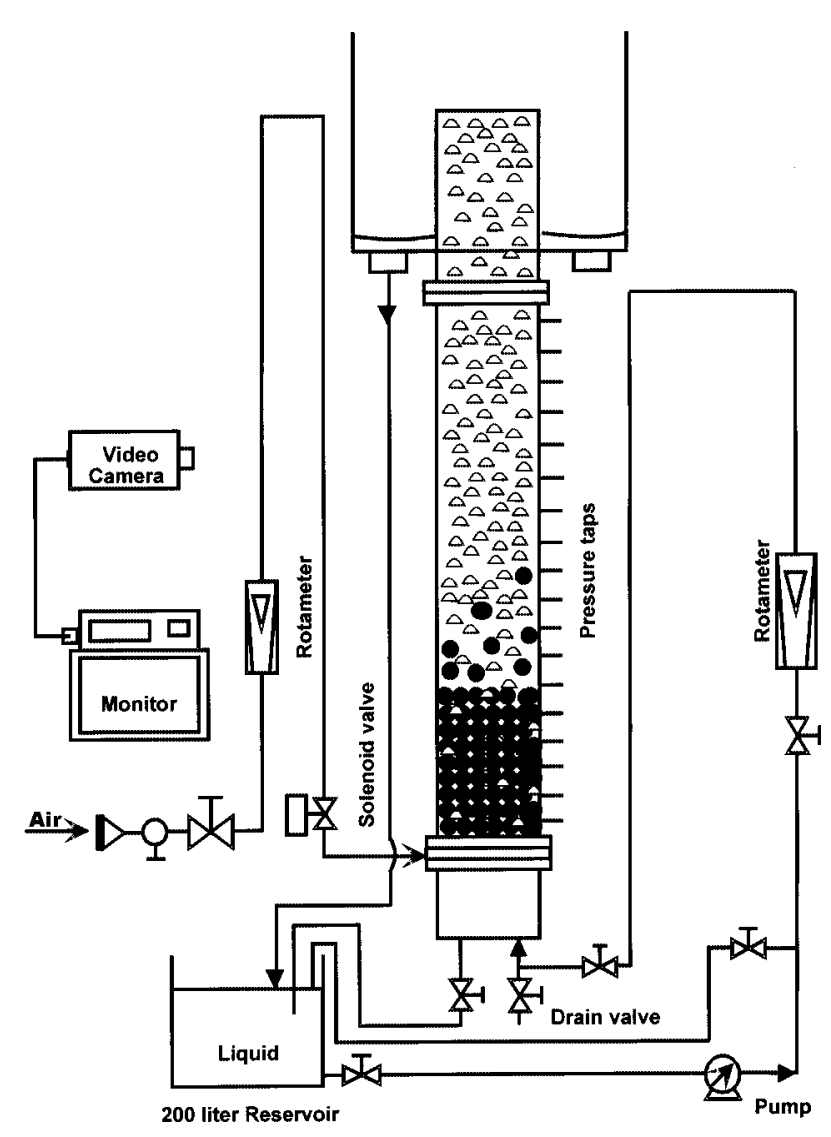

Fig. 2. Schematic diagram of experimental equipment.

and gas phases. Static bed height $\left(\mathrm{H}_{B 0}\right)$ was always maintained higher than $0.5 \mathrm{~m}$. The gas $(0.0-0.064 \mathrm{~m} / \mathrm{s})$ and liquid $(0.0-0.133 \mathrm{~m} / \mathrm{s})$ flow rates were measured by flowmeters. The liquid was introduced into the plenum chamber in which 40-mm glass balls were packed and then sent through a perforated liquid distributor plate containing 35 evenly spaced holes $(3 \mathrm{~mm})$ into the main fluidized bed. Air was introduced into the bed through ten evenly spaced perforated feed 
pipes with 33 upward-facing holes of $1.0 \mathrm{~mm}$ diameter on top of the liquid distributor. The static pressure drops in the beds were measured by differential pressure transducers (Omega, model PX771A100WCDI) connected to pressure taps which were mounted flush with the column wall at $0.1 \mathrm{~m}$ height intervals starting from $0.06 \mathrm{~m}$ above the liquid distributor. The transducer signals were stored in, and processed by, a PC at a sampling rate of $10 \mathrm{~Hz}$ with time intervals of $60 \mathrm{~s}$. The individual phase holdups were determined from the static pressure drop, expanded bed height and solid weight in the bed as

$$
\begin{aligned}
& -\frac{\Delta \mathrm{P}}{\Delta \mathrm{z}}=\left(\varepsilon_{g 0} \rho_{g}+\varepsilon_{l 0} \rho_{l}+\varepsilon_{s 0} \rho_{s}\right) \mathrm{g} \\
& \varepsilon_{g 0}+\varepsilon_{l 0}+\varepsilon_{s 0}=1.0 \\
& \varepsilon_{s 0}=\frac{\mathrm{M}_{p} / \rho_{s}}{\frac{\pi}{4} \mathrm{D}_{t}^{2} \frac{1}{2} \mathrm{H}_{B}}
\end{aligned}
$$

To measure the bubble drift velocity by the bed collapse technique, the experiments should be performed in the dispersed bubble flow regime of three-phase fluidized beds. A flow regime map of a three-phase fluidized bed (air-water- $4.5 \mathrm{~mm}$ glass beads) reported by Zhang et al. [1997] is shown in Fig. 3. It has been reported that three-phase fluidized beds can be classified as bubble coalescing and disintegrating beds based on particle size [Kim et al., 1972]. In the air-water-glass beads system, particle size larger than $2.5 \mathrm{~mm}$ lies in the bubble disintegrating regime. Since $3.1 \mathrm{~mm}$ glass beads were employed in three-phase fluidized beds by Chen and Fan [1990], the system may operate in the bubble disintegrating regime in the gas velocity range of $0-0.025 \mathrm{~m} / \mathrm{s}$. Over this gas velocity range, the system operation can be classified as the dispersed bubble flow regime, as observed visually.

In the dynamic experiments, when the system reached steady state at the given gas and liquid velocities, a solenoid valve in the gas supply line was quickly closed to cut-off the gas supply, and then the expanded bed height collapsed suddenly. The transient behaviour of the bed collapse after shut-off the gas supply was monitored by a video-camera. The upward moving velocity of the bub-

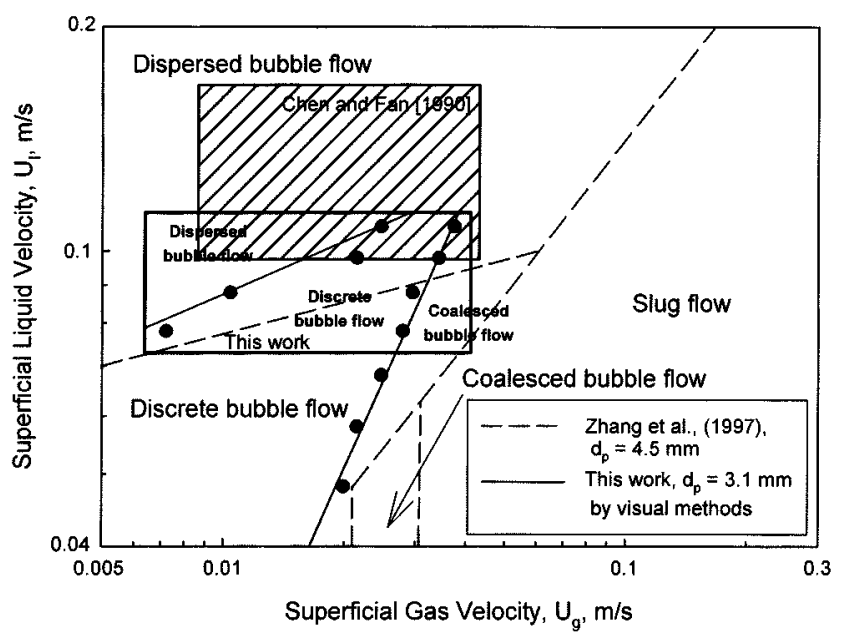

Fig. 3. Comparison of flow regime boundaries.

ble-free bed surface is the experimental value of $C_{1}$ in Eq. (7).

\section{RESULTS AND DISCUSSION}

A sample of the bed collapse process was monitored by a videocamera as shown in Fig. 4. As can be seen, the rising bubbles were very small and uniform in size. Lee et al. [2003] recently reported a series of snapshots of the bed height after shutting off the gas supply at $\mathrm{U}_{l}=19.8$ and $\mathrm{U}_{g}=19.4 \mathrm{~mm} / \mathrm{s}$ in the air-water- $3.2 \mathrm{~mm}$ polymer beads (density $=1,280 \mathrm{~kg} / \mathrm{m}^{3}$ ) system. They observed bubble coalescence with the system operating a in heterogeneous phase that contains both large and small bubbles. As reported by Lee et al. [2003], ambiguity of the bed surface is attributed to the entrained particles before cutting-off of the air supply ( $\mathrm{t} \leq 0)$, and those particles move downward due to gravity after the air supply is cut off. However, as can be seen in Fig. 4, in the bed of $3.1 \mathrm{~mm}$ glass beads at a relatively low gas velocity of $6.8 \mathrm{~mm} / \mathrm{s}$, the system was operating in the dispersed bubble flow regime where the bubbles were very small and uniform. Therefore, particles were not entrained by the exiting gas so that the bed height could be observed clearly.

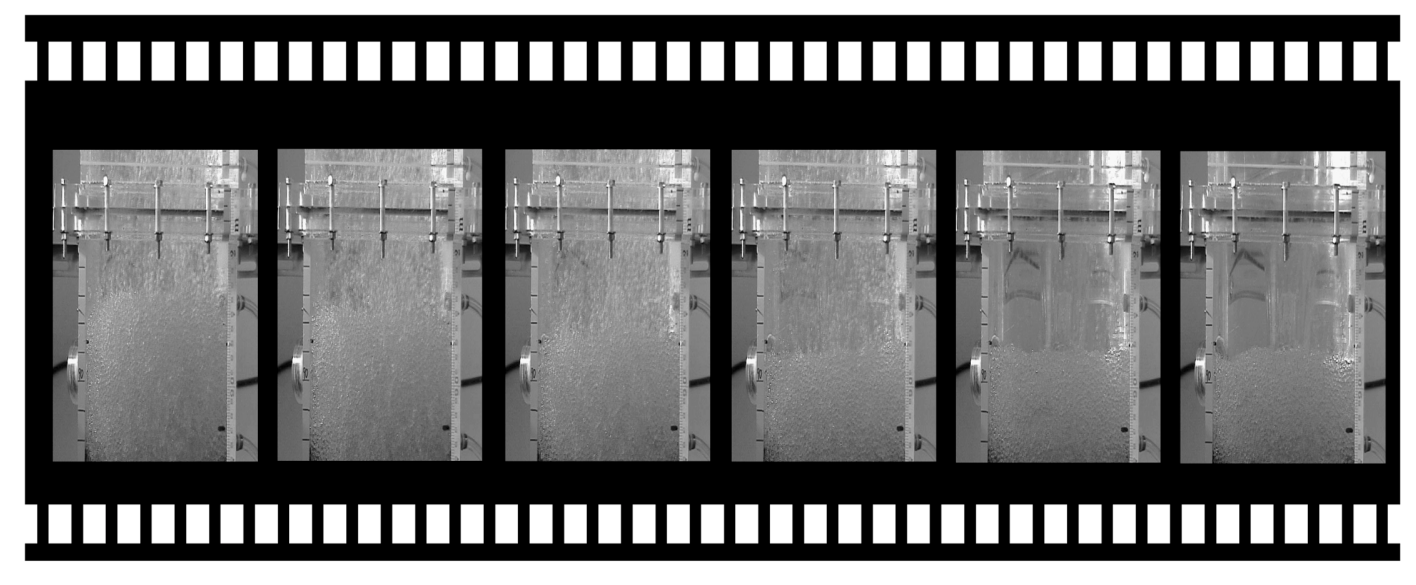

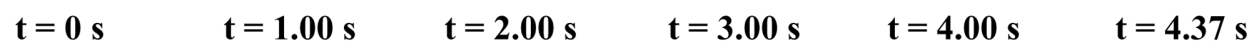

Fig. 4. Series of snapshots of bed surface after shutting off of gas supply at $U_{l}=0.103 \mathrm{~m} / \mathrm{s}, U_{g}=0.01 \mathrm{~m} / \mathrm{s}$.

March, 2005 


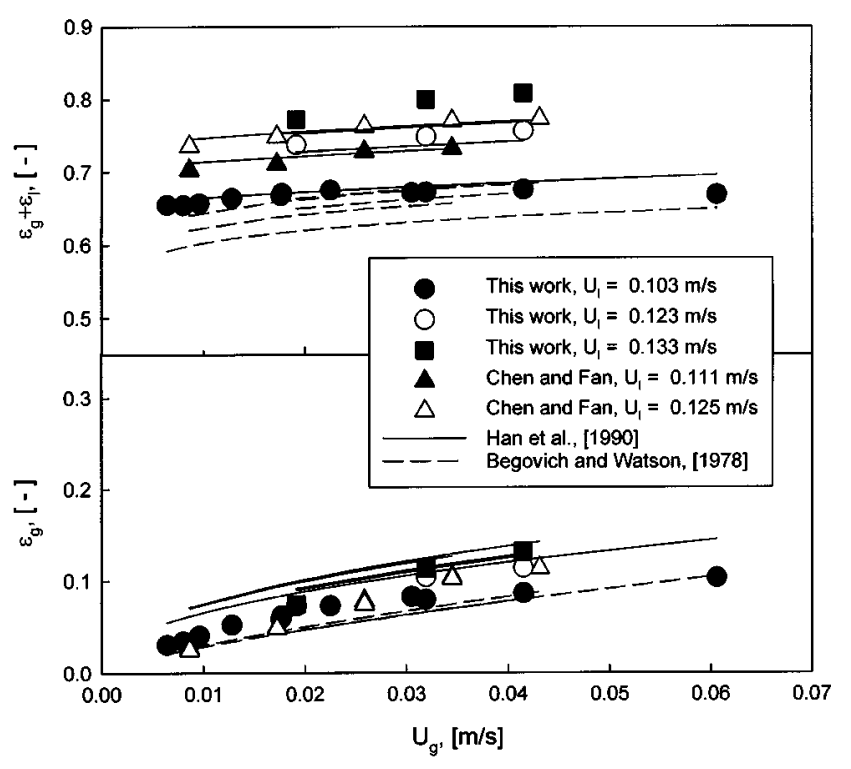

Fig. 5. Variation of gas holdup and bed voidage with gas superficial velocity.

The effect of gas velocity on gas holdup and bed voidage is shown in Fig. 5. As can be seen, both gas holdup and bed voidage increase with increasing gas velocity [Chen and Fan, 1990]. Recently, Larachi et al. [2001] have reported a state-of-the-art correlation for evaluating the macroscopic hydrodynamics of cocurrent upflow three-phase fluidized beds. They claimed that among the various gas phase holdup correlations for three-phase fluidized beds, the correlation of Begovich and Watson [1978] gives the smallest average absolute relative error (AARE). Also, Han et al. [1990] proposed liquid holdup and bed voidage correlations for three-phase fluidized beds in the bubble coalescing and disintegrating flow regimes, respectively. The solid lines in Fig. 5 were obtained from the correlation of Han et al. [1990], and the dotted lines were calculated from the Begovich and Watson's dimensional correlation [1978]. The three-phase fluidized bed of $3.1 \mathrm{~mm}$ glass beads was operating in the bubble disintegrating regime where both gas phase holdup and bed voidage

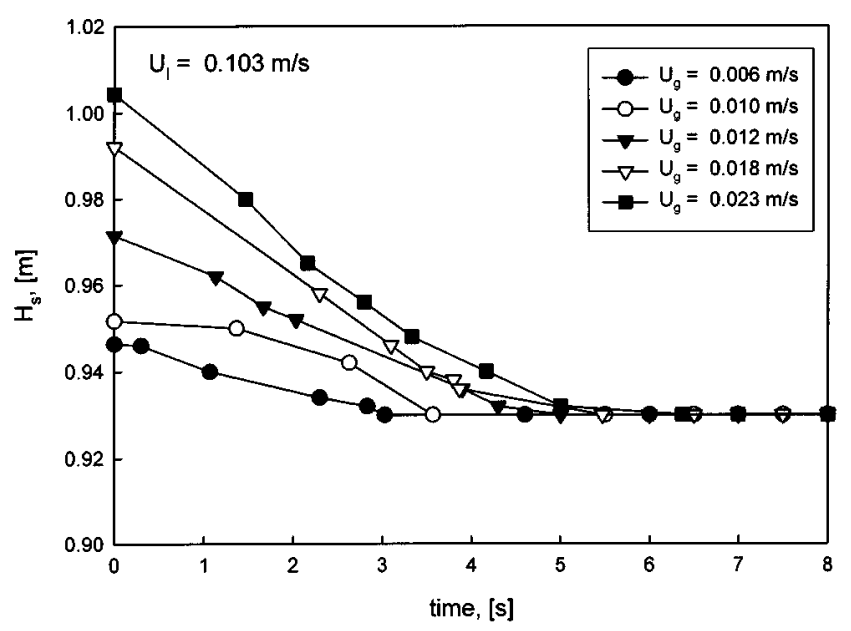

Fig. 6. Variation of the bed surface with elapsed time after the gas supply is cut off.

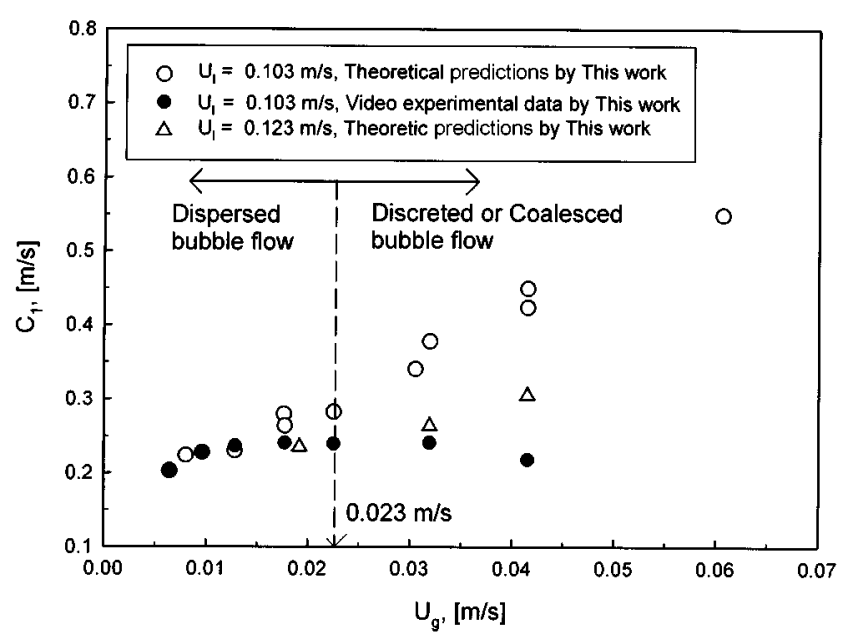

Fig. 7. Effect of gas velocity on $\mathbf{C}_{1}$, the velocity of moving boundary 1.

increase with increasing gas velocity. The measured phase holdups of each phase at steady state were used to calculate the bubble drift velocity (Eq. (11)) or velocity of moving boundaries 1 and $2\left(\mathrm{C}_{1}\right.$ and $C_{2}$ ). As can be seen in Fig. 5, the correlation of Han et al. [1990] predicts the experimental values reasonably well.

Variation of the bed surface with elapsed time after the gas supply was cut-off is shown in Fig. 6. As can be expected, the bed height of the three-phase fluidized bed was higher than that of the liquidsolid fluidized bed since the bed height increases with increasing gas velocity. When the air supply is cut off, the height of the bed surface decreases with elapsed time, and then reaches the bed height corresponding to that of liquid-solid fluidized bed, as observed by Jin and Zhang [1990] and Chen and Fan [1990]. Therefore, with these results, the velocity of moving boundary $1\left(\mathrm{C}_{1}\right)$ was measured as a function of time by using Eq. (11), and the bubble drift velocity, $\mathrm{U}_{b d}$, was determined experimentally.

Variation of the experimental and theoretical values of the velocity of the boundary 1 as a function of gas velocity is shown in Fig. 7. As can be seen in Fig. 3, at a liquid velocity of $0.103 \mathrm{~m} / \mathrm{s}$ and gas velocity of $0-0.023 \mathrm{~m} / \mathrm{s}$, bubble size was uniform in the dispersed bubble flow regime. However, as the gas velocity increased above $0.023 \mathrm{~m} / \mathrm{s}$, the discrete or coalesced bubble flow regime can be observed. As can be seen in Fig. 7, the experimental values of $\mathrm{C}_{1}$, the velocity of boundary 1 , do not vary significantly with gas velocity, whereas the theoretical values of $\mathrm{C}_{1}$ increase with gas velocity. The agreement between the experimental and theoretical values of $\mathrm{C}_{1}$ is fairly good at lower gas velocities, whereas the agreement becomes poorer with increasing gas velocity due to the change of flow regimes as a function of gas velocity as reported by Chen and Fan [1990] that, namely a transition from the dispersed bubble flow regime to the discrete or coalesced bubble flow regime.

The experimental and predicted values of bubble drift velocity $\left(\mathrm{U}_{b d}\right)$ as a function of gas velocity in three-phase fluidized beds are shown in Fig. 8 at a liquid velocity of $0.103 \mathrm{~m} / \mathrm{s}$. As shown in Fig. 3 , at a liquid velocity of $0.103 \mathrm{~m} / \mathrm{s}$ and gas velocities up to $0.023 \mathrm{~m} /$ $\mathrm{s}$, the dispersed uniform bubble flow regime was observed, but at higher gas velocities $\left(\mathrm{U}_{g}>0.023 \mathrm{~m} / \mathrm{s}\right)$, the discrete or coalesced bubble flow regime was observed. Also, the experimental and theoret- 


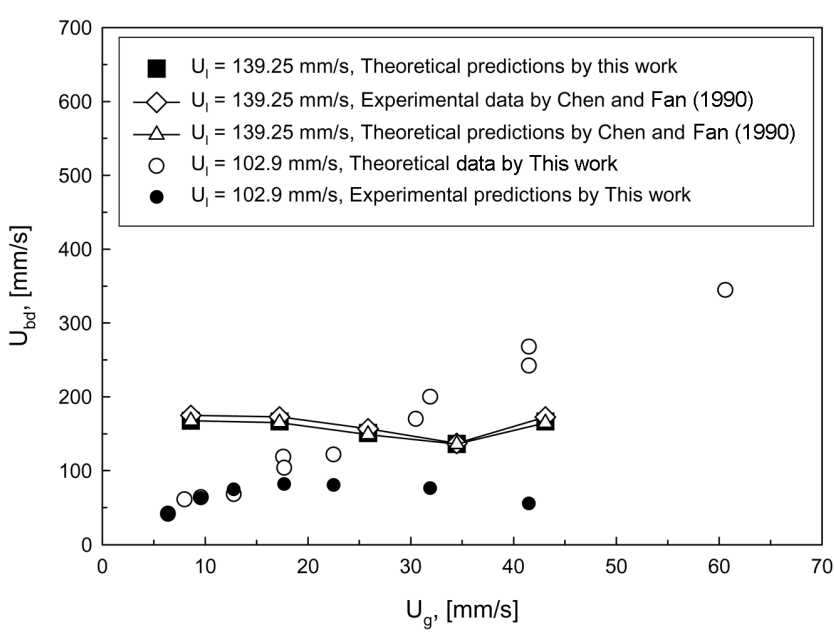

Fig. 8. Effect of gas velocity on bubble drift velocity, $\mathbf{U}_{b d}$.

ical values of bubble drift velocity, $\mathrm{U}_{b d}$, of Chen and Fan [1990] at liquid velocity of $0.139 \mathrm{~m} / \mathrm{s}$ are shown in Fig. 8 . One set of the theoretical values is based on the data of Chen and Fan [1990] and the other set corresponds to predicted ones from Eqs. (10) and (11). As can be seen, at lower gas velocities the agreement between the predicted and experimental values is acceptable, but the agreement becomes poorer with increasing gas velocity. This difference may be attributed to the difference in experimental method and the geometry of the experimental equipment. Therefore, further work is needed to clarify this difference measuring bubble size in three-phase fluidized beds.

\section{CONCLUSION}

In a three-phase fluidized bed of $3.1 \mathrm{~mm}$ glass beads fluidized by air and water, the dispersed bubble flow regime was observed visually using the bed collapse technique. Based on the theory, the bubble drift velocity initially decreases somewhat and starts to increase with increasing gas velocity after the transition of flow regimes occurs. However, there is some disagreement between the theory and the experimental data of bubble drift velocity due to the differences in bed collapsing technique and the bed geometry. Further work is needed to clarify these differences from bubble size measurements.

\section{ACKNOWLEDGMENT}

This work was supported by grant number (R-01-2003-00010028-0) from the Basic Program of the Korea Science and Engineering Foundation.

\section{NOMENCLATURE}

$-\Delta \mathrm{P}:$ total pressure drop $[\mathrm{Pa}]$

$\mathrm{C}_{1}$ : velocity of moving boundary $1[\mathrm{~m} / \mathrm{s}]$

$\mathrm{C}_{2}$ : velocity of moving boundary $2[\mathrm{~m} / \mathrm{s}]$

$\mathrm{d}_{p} \quad$ : particle diameter [mm]

$\mathrm{D}_{t} \quad$ : column diameter [m]

g : acceleration of gravity $\left[\mathrm{m} / \mathrm{s}^{2}\right]$
$\mathrm{H}_{B}$ : bed height [m]

$\mathrm{H}_{B 1}$ : bed height of boundary 1 in Fig. 1 [m]

$\mathrm{H}_{B 2}$ : bed height of boundary 2 in Fig. 1 [m]

$\mathrm{j}_{g l} \quad$ : gas drift flux [m/s]

$\mathrm{M}_{p} \quad$ : particle inventory [kg]

$\mathrm{t}$ : elapsed time after cut-off the air supply [s]

$\mathrm{U}_{b} \quad$ : bubble rise velocity $[\mathrm{m} / \mathrm{s}]$

$\mathrm{U}_{b d} \quad$ : bubble drift velocity in three-phase fluidized beds [m/s]

$\mathrm{U}_{g 0} \quad$ : superficial gas velocity $[\mathrm{m} / \mathrm{s}]$

$\mathrm{U}_{10}$ : superficial liquid velocity $[\mathrm{m} / \mathrm{s}]$

$\mathrm{V}_{g^{2}} \quad$ : gas velocity in region $2[\mathrm{~m} / \mathrm{s}]$

$\mathrm{V}_{l 1}$ : liquid velocity in region $1[\mathrm{~m} / \mathrm{s}]$

$\mathrm{V}_{12}$ : liquid velocity in region $2[\mathrm{~m} / \mathrm{s}]$

$\mathrm{V}_{s 1} \quad$ : solid velocity in region $1[\mathrm{~m} / \mathrm{s}]$

$\mathrm{V}_{s 2} \quad$ : solid velocity in region $2[\mathrm{~m} / \mathrm{s}]$

$\mathrm{z}$ : axial bed height $[\mathrm{m}]$

\section{Greek Letters}

$\varepsilon_{g 0} \quad$ : gas holdup in three-phase fluidized beds [-]

$\varepsilon_{l 0} \quad$ : liquid holdup in three-phase fluidized beds [-]

$\varepsilon_{l}^{\prime \prime} \quad$ : liquid holdup in two-phase fluidized beds [-]

$\varepsilon_{s 0} \quad:$ solid holdup in three-phase fluidized beds [-]

$\rho_{g} \quad$ : gas density $\left[\mathrm{kg} / \mathrm{m}^{3}\right]$

$\rho_{l} \quad:$ liquid density $\left[\mathrm{kg} / \mathrm{m}^{3}\right]$

$\rho_{s} \quad$ : solid density $\left[\mathrm{kg} / \mathrm{m}^{3}\right]$

\section{REFERENCES}

Begovich, J. M. and Watson, J. S., Hydrodynamic Characteristics of Three-Phase Fluidized Beds, Fluidization, Davidson, J. F. and Keairns, D. L. eds, Cambridge University Press, Cambridge, U. K., 190 (1978).

Bhatia, V. K. and Epstein, N., Three-Phase Fluidization: A Generalized Wake Model, Fluidization and Its Applications, Cepadeus-Editions, Toulouse (France), 380 (1974).

Chen, Y. M. and Fan, L. S., "Drift Flux in Gas-Liquid-Solid Fluidized Systems from the Dynamics of Bed Collapse,' Chem. Eng. Sci., 45, 935 (1990).

Chern, S.-H., Fan, L.-S. and Muroyama, K., "Hydrodynamic of Cocurrent Gas-Liquid-Solid Semifluidization with Liquid as the Continuous Phase," AIChE J., 30, 288 (1984).

El-Temtamy, S. A. and Epstein, N., "Rise Velocities of Large Single TwoDimensional and Three-Dimensional Gas Bubbles in Liquids and in Liquid-Fluidized Beds,' Chem. Eng. J., 19, 153 (1980).

Fan, L. S., Gas-Liquid-Solid Fluidization Engineering, Butterworth, Stoneham, MA (1989).

Han, H. D., Lee, W., Kim, Y. K., Kwon, J. L., Choi, H. S. and Kang, Y., "Phase Holdup and Critical Fluidization Velocity in a Three-Phase Inverse Fluidized Bed,' Korean J. Chem. Eng., 20, 163 (2003).

Han, J. H., Wild, G. and Kim, S. D., "Phase Holdup Characteristics in Three-Phase Fluidized Beds,' Chem Eng. J., 43, 67 (1990).

Jin, Y. and Zhang, J. P., "Bed Collapse Technique for Estimating Parameters of Generalized Wake Model for a Three-Phase Fluidized Bed,' Proc. $5^{\text {th }}$ Chinese National Fluidization Conference, Beijing, 327 (1990).

Kim, S. D., Baker, C. G. J. and Bergougnou, "Holdup and Axial Mixing Characteristics of Two and Three Phase Fluidized Beds,' Can. J. 
of Chem. Eng., 50, 695 (1972).

Kwauk, M., Fluidization: Idealized and Bubbleless, with Application, Science Press and Ellis Horwood, Beijing (1992).

Larachi, G., Beltares, L., Iliuta, I. and Grandjean, B. P. A., "Three-Phase Fluidization Macroscopic Hydrodynamics Revisited,' Ind. Eng. Chem. Res., 40, 993 (2001).

Lee, D. H., Epstein, N. and Grace, J. R., "Hydrodynamic Transition from Fixed to Fully Fluidized beds for Three-Phase Inverse Fluidization," Korean J. Chem. Eng., 17, 684 (2000).

Lee, D. H., Park, S. S., Choi, W. W., Kim, D. J., Kim, J.-H., Lee, Y. K., Sim, S. J. and Kim, S. D., "Dynamic Characteristics of Bed Collapse in Three-Phase Fluidized Beds,' Korean J. Chem. Eng., 20, 1166 (2003).

Lee, D. L., Kim, J. O. and Kim S. D., "Mass Transfer and Phase Holdup
Characteristics in Three-Phase Fluidized Beds,' Chem. Eng. Comm., 119, 179 (1993).

Maucci, E., Briens, C. L., Martinuzzi, R. J. and Wild, G., "Detection and Characterization of Piston Flow Regime in Three-Phase Fluidized Beds,' Powder Techn., 103, 243 (1999).

Park, S. H. and Kim, S. D., "Experimental, Statistical and Stochastic Studies of Pressure Fluctuations in a Three-Phase Fluidized Bed with a Moderately Large Diameter,' Korean J. Chem. Eng., 20, 121 (2003).

Saberian-Beoudjenni, M., Wild, G., Charpentier, J. C., Fortin, Y., Euzen, J.-P. and Patoux, R., "Contribution to the Hydrodynamics Study of Fluidized Gas-Liquid-Solid Reactors,' Entropie, 120, 30 (1984).

Zhang, J. P., Grace, J. R. and Epstein, N., "Flow Regime Identification in Gas-Liquid Flow and Three-Phase Fluidized Beds,' Chem Eng. Sci., 52, 3979 (1997). 